\title{
Corn Silk as Corrosion Inhibitor for Mild Steel in 0.1M HCl Medium
}

\author{
K. Okorosaye - Orubite ${ }^{*}$ and N. C Ngobiri \\ Department of Pure and Industrial Chemistry, University of Port Harcourt, P.M.B.5323, Port Harcourt, \\ Nigeria. Rivers State
}

\begin{abstract}
The effectiveness of corn silk water extract (CSWE) as corrosion inhibitor of mild steel in $0.5 \mathrm{M} \mathrm{HCl}$ solution at $303 \mathrm{~K}, 313 \mathrm{~K}$ and $323 \mathrm{~K}$ was investigated in this work. Various concentrations of CSWE $(5 \% \mathrm{v} / \mathrm{v}$, $10 \% \mathrm{v} / \mathrm{v}$, and $15 \%$ and $20 \% \mathrm{v} / \mathrm{v}$ ) were prepared from dried corn silk. The study was carried out using weight loss and AAS analysis. The results of the AAS analysis collaborated weight loss measurements on the efficiency of CSWE as corrosion inhibitor. Inhibition efficiency of $77.7 \%$ and $72.0 \%$ was obtained respectively using both methods. Inhibition efficiency increased with increase in concentration of CSWE $(5 \% v / v<10 \% v / v<15 \%<20 \%$ $v / v)$ while corrosion rate decreased as concentration increased. Increase in temperature reduced inhibition efficiency and CSWE was shown to be most effective at $303 \mathrm{~K}$ than at $313 \mathrm{~K}$ and $323 \mathrm{~K}$. Kinetic study of the process proposed a first order reaction type. From thermodynamic parameters, inhibition was attributed to the existence of a protective film on metal surface by interaction between inhibitor molecules and metal ions in solution..Reaction rate constant values calculated were $0.0234,0.0818$ and 0.104 for the blank solution and $0.0049,0.0328,0.0416$ for the highest inhibitor concentration of $20 \% \mathrm{v} / \mathrm{v}$ respectively at the different temperatures studied.Data obtained were subjected to Langmuir, Temkin and Frendlich isotherms. Langmuir model was found to be most fitted of the three models. The utility of a waste material as corrosion inhibitor is once more reported.
\end{abstract}

Keywords:inhibition, efficiency, corn silk, water extract, AAS, first order.

\section{Introduction}

Corrosion of metals is a natural phenomenon which proceeds until inhibited. Since metals are used in different technological structures and in various environments protecting metallic structures is pertinent. Specifically, iron and its alloys find use as mechanical structures in industries where they come in contact with mineral acids such as $\mathrm{HCl}$. Mineral acids are used for pickling and cleaning metal surfaces. $\mathrm{HCl}$ has been found more economical that other mineral acids (Ebenso et al). One of the effective ways of protecting such metal surfaces is the addition of inhibitors to the acid medium. Many inhibitors, organic and inorganic have been reported as metallic corrosion inhibitors (Nahle, 2005). Recent researches on corrosion inhibition had centred on natural inhibitors which are non toxic, eco friendly and readily available obtained from plants. Carica papaya (Okoafor and Ebenso 2010) water hyacinth (Oloruntoba et al2012), Sidaacuta (Eduok 2012),Ficustricopoda Eddyet al 2012), JathroCurcas(Olusegun et al2013). Plants materials as metallic corrosion inhibitors have been reported Rice husk (Alaneme 2015), Corn water (Yusuf et al 2013), Agricultural bye products (Magarita et al 2012). Some economic plants have also been reported (Rehan 2003). Most of these plants are part of the food chain in most societies. Their use as corrosion inhibitors may likely cause a competitive demand in the food chain. Utilization of plant materials that are of less economic importance, or regarded as waste material would not only find use for these materials but also make the environment greener. This is the basis of using corn silk in this research wok.

Corn silks are a bundle of silky, long and yellowish strands on top of the corn fruit. When matured corn plant is harvested corn silks are discarded while the fruit is prepared for meals. However some traditional use of corn silk has been reported (Maksimovic 2003, Velazquez 2012, and Guoet al 2009). The phytochemical composition of corn silk contains flavonoids, terpenoids and phenolic compounds which are effective as anti-oxidants and antibacterial (Tian et al 2013). An antioxidant can inhibit, or delay oxidation process although at lower concentration than the bio molecule it is protecting. Natural anti-oxidants find use as food preservatives and other health benefits (Nurhanan and Wan 2013). The aqueous extract of corn silk has properties that act as strong inhibitor for crystallization of calcium oxalate monohydrate stones. The inhibition was interpreted in terms of adsorption on the active growth sites of the crystal surface (Alaemary 2016).Flavonoids, Tannins, oils and phenolic pigments generally have conjugated aromatic structure, long aliphatic chains such as $\mathrm{N}, \mathrm{S}$, and $\mathrm{O}$ heteroatom with free electro pairs that are available to bond with metal surface (Paulina Arellanes- Lozada et al 2014). Yusuf et al (2013) reported the evaluation of corn water for corrosion inhibitors. Their work concluded that corn water contains nitrites, phosphates and silicates and indeed a source of organic inhibitor extract for metal corrosion inhibition. The use of corn silk as corrosion inhibitor has not been reported. The aim of this work is to investigate the effectiveness of corn silk water extract (CSWE) as corrosion inhibitor for mild steel in $0.5 \mathrm{M} \mathrm{HCl}$ medium at $303 \mathrm{~K}, 313 \mathrm{~K}$, and $323 \mathrm{~K}$. 


\section{Materials And Methods}

The corrosive environment, $0.5 \mathrm{M} \mathrm{HCl}$ prepared according to known standards. Mild steel sheets with composition, (C, $0.16-18 \%$, Mn $0.7-0.9 \%$, P $0.04 \%$, Si $0.40 \%$ and S, $0.04 \%$ ) were obtained from the Engineering workshop of the university of Port Harcourt Choba Rivers State Nigeria. They were cut into $4 \mathrm{~cm} / 3 \mathrm{~cm}$ sizes of $1.0 \mathrm{~mm}$ thickness. The coupons were perforated at the top center with holes of diameter $2.0 \mathrm{~mm}$ to allow passage of thread. They were mechanically cleaned and scrubbed with sandpaper to expose shining surfaces, degreased in absolute ethanol and dipped in acetone and finally dried in an oven at $40^{\circ} \mathrm{C}$. Dried coupons were stored in a desiccators before use. The initial weight of the coupons was taken using an analytical weighing balance. Each weight was an average of three replicate measurements. The months of April to September are usually the season for harvesting corn in Nigeria. It is common place to see local women selling cooked corn on the roadsides to individuals. Corn silk was obtained from these vendors at the East-West road junction of the University of Port-Harcourt. They were rinsed with deionised water to remove sand and dirt, sun dried and further dried in an oven at $60^{\circ} \mathrm{Cfor} 3$ hours. Dried corn silks were ground to powder form, thereafter $90 \mathrm{~g}$ of dried corn silk were soaked in one liter of deionised water for 48 hours. The mixture was filtered with a whatman filter paper to separate filtrate from residue. The filtration process was done severally to obtain a clear solution. This was labeled as the stock solution or corn silk water extracts (CSWE).

\section{Serial Dilution}

Different volumes of the stock solution were measured into four beakers. The volume in each better made up to $100 \mathrm{ml}$ by the prepared $0.5 \mathrm{M}$. $\mathrm{HCl}$, these were the test solutions;

$50 \% v / v(95 \mathrm{ml}$ of $0.5 \mathrm{M} \mathrm{HCl}+5 \mathrm{ml}$ of extract $)$

$10 \% v / v(90 \mathrm{ml}$ of $0.5 \mathrm{M} \mathrm{HCl}+10 \mathrm{ml}$ of extract)

$10 \% v / v(85 \mathrm{ml}$ of $0.5 \mathrm{M} \mathrm{HCl}+15 \mathrm{ml}$ of extract $)$

$20 \% v / v(85 \mathrm{ml}$ of $0.5 \mathrm{M} \mathrm{HCl}+20 \mathrm{ml}$ of extract)

A fifth beaker contained only $0.5 \mathrm{M} \mathrm{HCl}$.

\section{Weight Loss Measurement}

Five previously weighed coupons were plunged into the beakers containing various volumes of extract and $0.5 \mathrm{M} \mathrm{HCl}$. The coupons were retrieved after every 24 hours for interval of 7 day; washed, dried and weighed. Weight loss of coupons was calculated using the formulae,

$$
\begin{aligned}
& \Delta_{w}=w_{f-} w_{i} \ldots \ldots .(1) \text { Where } \Delta \mathrm{w}=\text { weight loss (gms) } \\
& w_{f}=\text { final weight of coupons } \\
& w_{i}=\text { initial weight of coupons }
\end{aligned}
$$

\section{Atomic Absorption Spectroscopy (AAS) Analysis}

Atomic absorption spectroscopy was conducted to determine the concentration of $\mathrm{Fe}^{2+}$ ions that leached into the $0.5 \mathrm{M} \mathrm{HCl}$ solution in the absence and presence of CSWE. An Avanta version 2.02 AAS was used. As the coupons are removed and washed every 24 hours for the weight loss measurement, the $0.5 \mathrm{M} \mathrm{HCl}$ solutions were taken to be tested for $\mathrm{Fe}^{2+}$ concentration in the solution. The first set of solutions were without CSWE extract which served as the blank while the second set contained the extract in the various concentrations.

\section{Results And Discussions}

Weight loss of mildsteel coupons in the absence and presence of CSWE $0.5 \mathrm{M} \mathrm{HCl}$ are presented in Fig. 1. The remarkable difference in weight loss on addition of CSWE reveals that it actually retarded mild steel corrosion. As evident in the graph, even the lowest concentration of 5\%v/v CSWE recorded a weight loss value lower than that of the blank (absence of inhibitor).

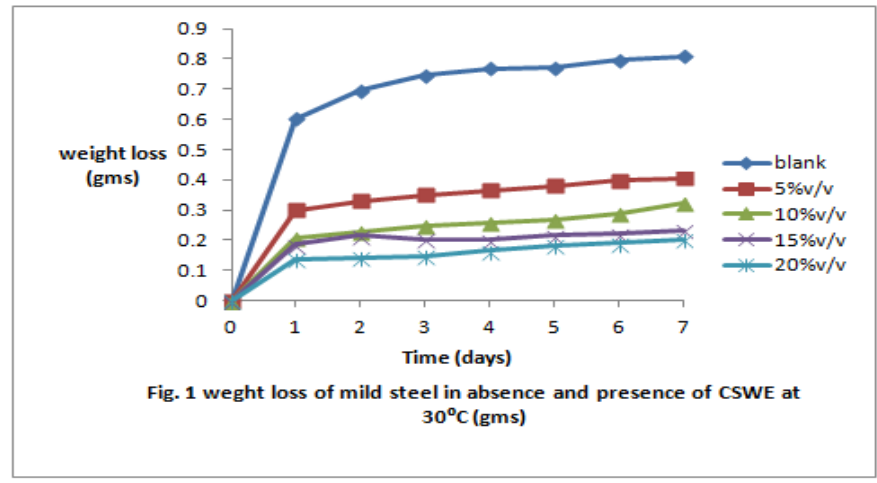


Plant extracts have been widely reported to inhibit metal corrosion and specifically mild steel corrosion in acid medium (Negm et al 2012, Khadijahet al 2015, Taissa et al 2015 and Hart 2016). Inhibition process was attributed to the formation of a surface film resulting from interaction between metal ions and inhibitor molecules. Cornsilk like most plants contains flavonoids and phenolic compounds. These all have anti oxidant activity and show good chelating behaviour with $\mathrm{Fe}^{2+}$ ions in solution. They may have formed a film, spread over metal surface causing a barrier between metal surface and corrosion environment $(0.5 \mathrm{M} \mathrm{HCl})(\mathrm{Ebrahim}$ Zadel et al 2008). The weight loss was observed to decrease with increase in concentration of inhibitor hence the weight loss value for $5 \% \mathrm{v} / \mathrm{v}$ is the lowest $(0.3001 \mathrm{gms})$ while $20 \% \mathrm{v} / \mathrm{v}$ recorded the highest $(0.1386 \mathrm{gms})$ on the first day of introduction of the extract. As concentration increased, more inhibitor molecules were available and deposited on metal surface. The separation between metal surface and acid solution thereby increased. This pattern of metal protection is reported for most plant extracts (Alanewe et al 2014, Rehan 2003). These are indications that CSWE has good corrosion inhibition performance.

The corrosion rate of mild steel in the absence and presence of CSWE was calculated at temperatures $303 \mathrm{~K}$, $313 \mathrm{~K}$ and $323 \mathrm{~K}$, using equation 2 below,

$C_{R}=\frac{K \Delta W}{D A T}$ (2) where $C_{R}$ is corrosion rate in $\mathrm{mm} / \mathrm{yr}, \mathrm{K}$ is constant $(87.6), \mathrm{D}$ is density $\left(\mathrm{g} / \mathrm{cm}^{3}\right), \mathrm{A}$ is area of the coupons $\left(\mathrm{cm}^{3}\right)$ and $\mathrm{T}$ is exposure time (hrs).

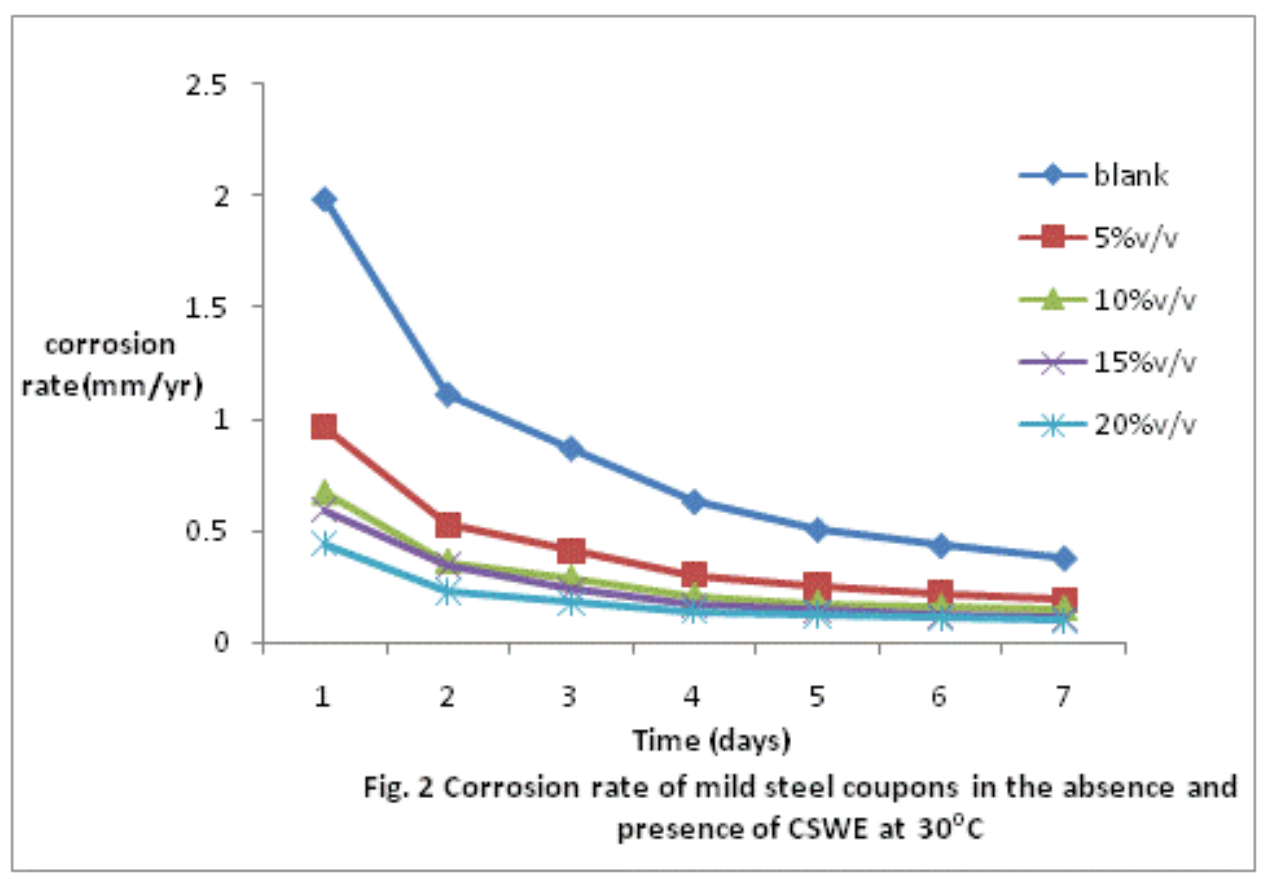

The plots are presented in Fig. 2. Corrosion rate followed same trend as weight loss data. The highest corrosion rate was observed in the absence of extract $(0.9603 \mathrm{~mm} / \mathrm{yr})$ and lowest for the highest extract concentration $20 \% \mathrm{v} / \mathrm{v}(0.44 \mathrm{~mm} / \mathrm{yr})$.Corrosion rate was also observed to decrease with time. In all the concentrations studied, the corrosion rate value was least on the first day and highest on the $7^{\text {th }}$ day.

The corrosion mitigation capacity is evaluated by the inhibition efficiency. For this study, the corrosion inhibition efficiency was calculated using the expression,

$1 \mathrm{E} \%=1-\frac{C_{\text {Rin } h}}{C_{\text {Rblank }}} x \frac{100}{1} \ldots \ldots \ldots \ldots . . . .3$

Where $C_{\text {Rinh }}$ and $C_{\text {Rblank }}$ represent corrosion rates in presence and absence of CSWE

The results are presented in Fig 3. As expected, corrosion inhibition efficiency increased with increase in concentration of CSWE. As concentration of extract increased more inhibitor molecules deposited on metal surface to cause a barrier between metal surface and corrosive molecules. Most plant extracts exhibit this behavioral pattern (El- Etre 2003, Okoafor 2014). 
Effect of time on inhibition efficiency.

The effect of time on inhibition efficiency is shown in Fig 3.

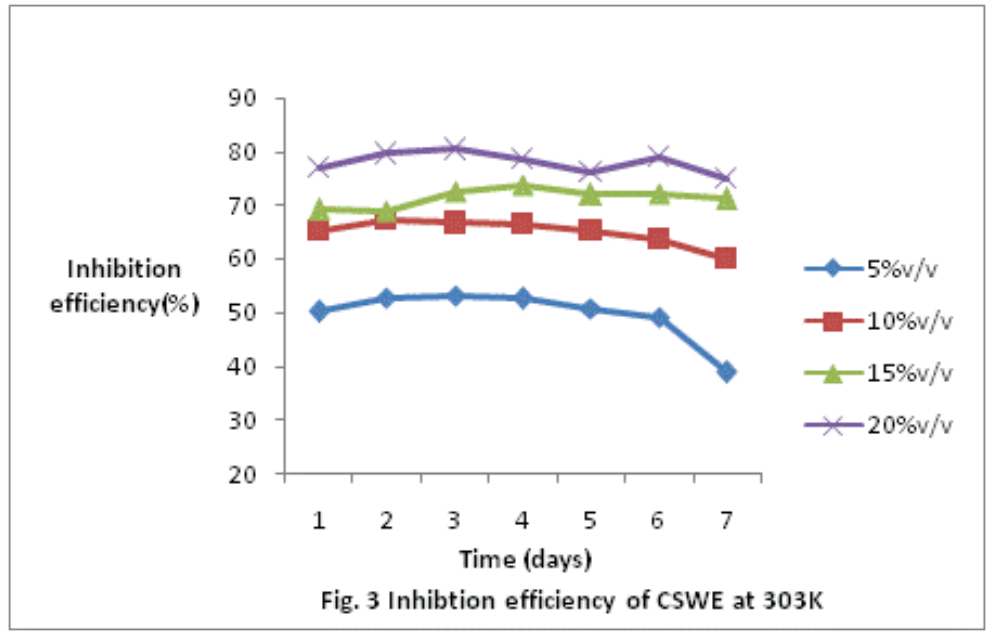

For all the concentrations studied, the inhibition efficiency increased progressively from the first day and was at maximum on the second or third day. It follows therefore that although inhibition efficiency is concentration dependent; the effectiveness of CSWE was limited to the first three days. Rehan (2003) observed similar trend studying the corrosion inhibition of steel in $0.2 \mathrm{M} \mathrm{HCl}$ by plant extracts, that the inhibition of reached maximum after a day and remained constant throughout the seven days of study. The bio degradable nature of the extract by microbes in the environment was given as reason for this observation. The gradual protection of mild steel surface within the first three days could probably be attributed to precipitation of corrosion products, mainly oxides, which blocked the metal surface in addition to CSWE molecules. Inhibition efficiency was at a maximum on the second day for concentration $5 \% \mathrm{v} / \mathrm{v}$ and $10 \% \mathrm{v} / \mathrm{v}$. As concentration increased to $15 \% \mathrm{v} / \mathrm{v}$ and $20 \% \mathrm{v} / \mathrm{v}$ maximum inhibition was observed on the $3^{\text {rd }}$ day. At lower CSWE concentration and on the $2^{\text {nd }}$ day fewer inhibitor molecules were available on mild steel surface while continued microbial activities break down surface film and exposed metal surface. Increase in concentration introduced more inhibitor molecules which slightly reduced the effect of the microbial activities on the protective film. This may explain the shift from $2^{\text {nd }}$ day to the $3^{\text {rd }}$ day. The maximum inhibition efficiency was observed on the $3^{\text {rd }}$ day for the $20 \% \mathrm{v} / \mathrm{vconcentration.}$

\section{Temperature dependence of inhibition efficiency}

The temperature dependence of the inhibition efficiency is similar to reports by other researchers (Alaneme 2015, Singh 2010). CSWE protection of mild steel surface was less efficient at higher temperatures of $40^{\circ} \mathrm{C}$ and $50^{\circ} \mathrm{C}$. Temperature has been known to increase the rate of most chemical reactions. Two reason may be deduced to explain this inhibition efficiency pattern; according to Singh (2010), at these higher temperatures there was increased rate of dissolution of mild steel and secondly partial desorption of the inhibitor molecules form the metal surface. The result is shown in Fig 4.

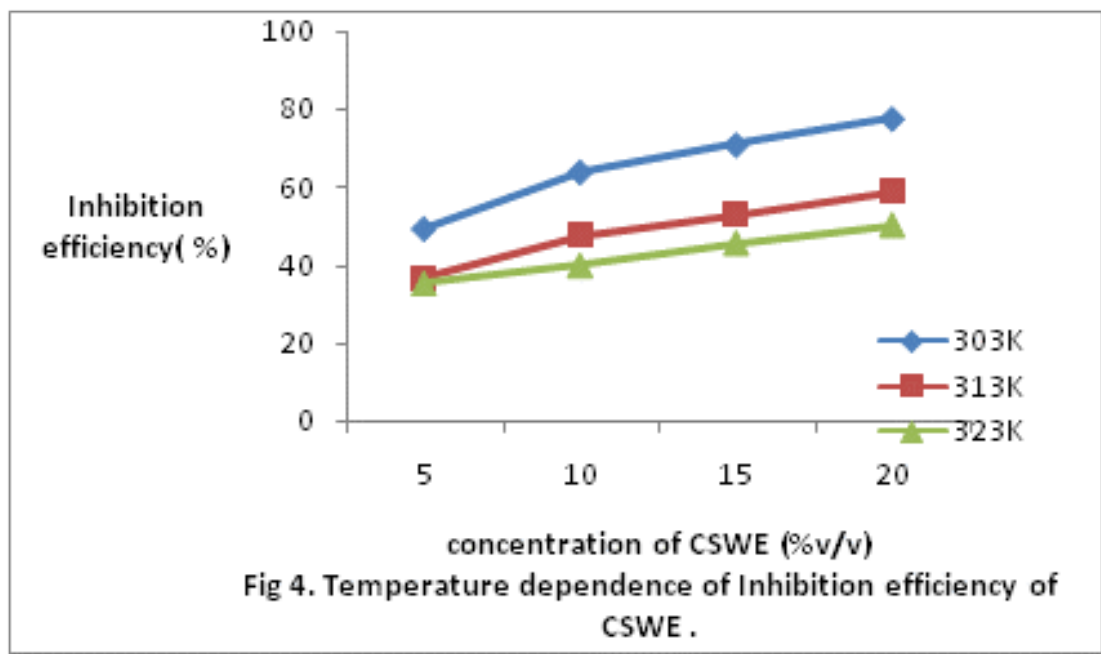




\section{TEMPERATURE DEPENDENCE OF CORROSION RATE.}

Corrosion rate increase with increase in temperature as expected. This is because at higher temperatures, reacting molecules gain more kinetic energy and speed up the corrosion reaction. The effect of concentration at these higher temperatures $(313 \mathrm{~K}, 323 \mathrm{~K})$ is still remarkable. Corrosion rate decreased with increase in concentration, depicting increase in inhibitor molecules and better coverage of metal surface. A corrosion rate at different temperatures is shown in Fig 5.

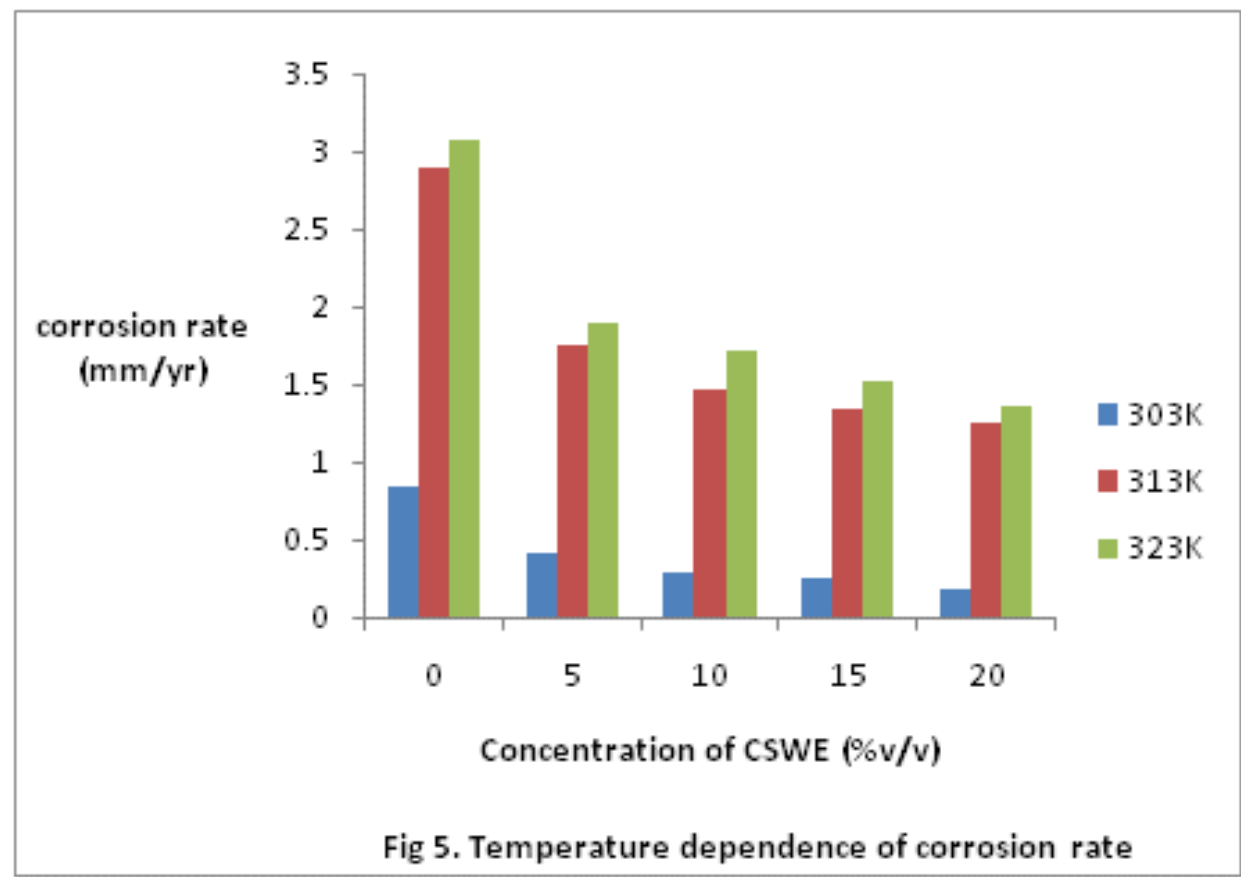

\section{Kinetics of the Corrosion Reaction}

Chemical kinetics includes investigations of how experimental conditions can influence the rate of a chemical reaction. The rate constant gives a direct measure of the relative corrosion rate; how fast or slow the reaction is, generally a small value equates a slow reaction while a large means reaction is rapid. For this study the rate constant was calculated using equation 4

$\mathrm{k}=\frac{2.303}{T} \log \frac{w_{i}}{w_{f}} \ldots . .4 \quad w_{i} \ltimes w_{f}$ are initial and final weights of coupon, $\mathrm{T}$ is temperature.

Calculated values are presented in Table 1. Rate constant for the blank solution (absence of CSWE) is obviously higher than rate constant for the solutions with various concentrations of CSWE. Rate constant values follow the pattern already described for corrosion rate and inhibition efficiency. It was lowest for the highest concentration of $20 \% \mathrm{v} / \mathrm{v}$ of CSWE.

Table 1. Inhibition efficiency and Rate constant atdifferent temperatures

\begin{tabular}{|c|c|c|c|c|c|c|}
\hline Conc. of CSWE & \multicolumn{3}{|c|}{ Inhibition efficiency } & \multicolumn{3}{|c|}{ Rate constant (k) } \\
\hline & $303 \mathrm{~K}$ & $313 \mathrm{~K}$ & $323 \mathrm{~K}$ & $303 \mathrm{~K}$ & $313 \mathrm{~K}$ & $323 \mathrm{~K}$ \\
\hline Blank & & & & 0.0234 & 0.0818 & 0.104 \\
\hline $5 \% \mathrm{v} / \mathrm{v}$ & 49.4 & 36.7 & 35.4 & 0.0114 & 0.0514 & 0.0635 \\
\hline $10 \% \mathrm{v} / \mathrm{v}$ & 64 & 47.7 & 40 & 0.0086 & 0.0423 & 0.0519 \\
\hline $15 \% \mathrm{v} / \mathrm{v}$ & 71 & 53 & 45.8 & 0.0067 & 0.0384 & 0.0471 \\
\hline $20 \% \mathrm{v} / \mathrm{v}$ & 77.7 & 59 & 50.4 & 0.0049 & 0.0328 & 0.0416 \\
\hline
\end{tabular}

Concentration of $\mathrm{Fe}^{2+}$ ions in solution.

This measurement was done to confirm the result of the weight loss experiment. Fig. 7 is a plot of the concentration of $\mathrm{Fe}^{2+}$ ions as mild steel coupons corrode in the absence and presence of CSWE. 


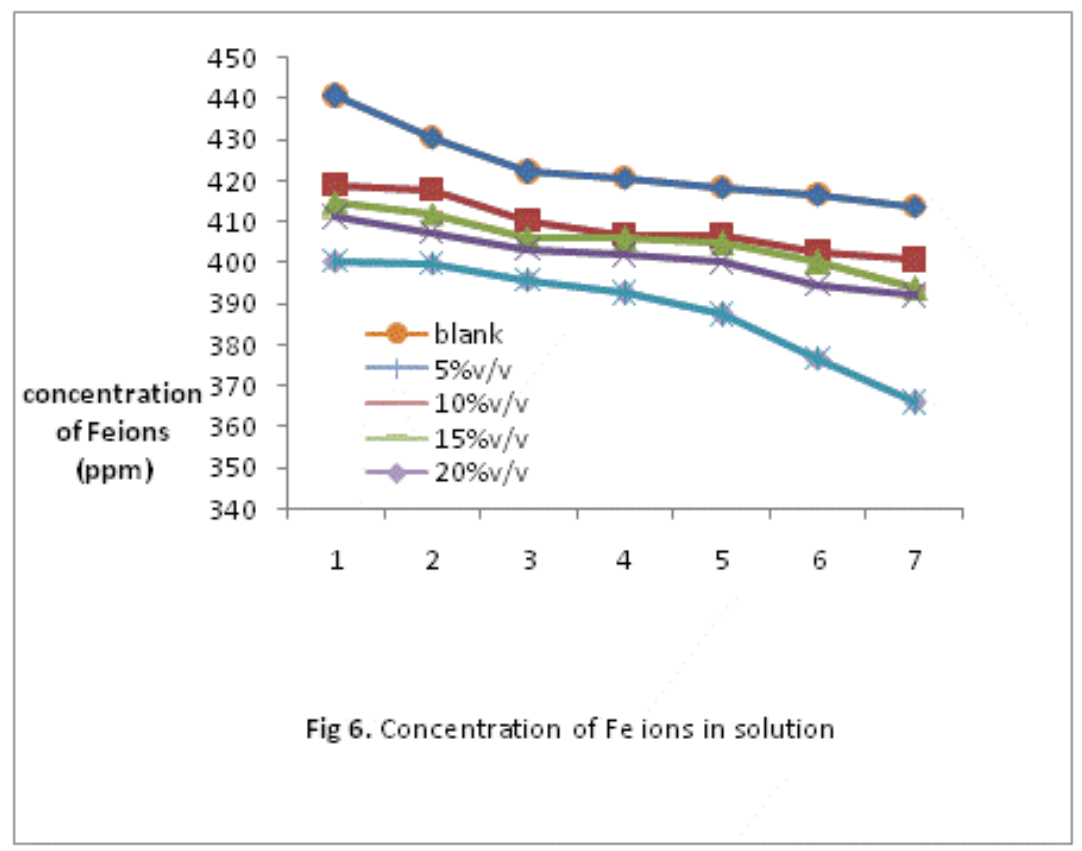

The result is similar to the weight loss data. There was an obvious decrease in concentration of $\mathrm{Fe}^{2+}$ ions as CSWE was added to the solution. This is a clear indication that the extract slowed down the dissolution of mild steel coupon. The concentration dependency of inhibition of mild steel was also confirmed by amount of $\mathrm{Fe}^{2+}$ ions in solution. AAS analysis shows that there was a steady decrease in concentration of $\mathrm{Fe}^{2+}$ ions as the concentration of CSWE increased from $5 \% \mathrm{v} / \mathrm{v}$ to $20 \% \mathrm{v} / \mathrm{v}$. An indication that more inhibitor molecules were available, the less $\mathrm{Fe}^{2+}$ ions produced by the oxidation reaction, $\mathrm{Fe} \longrightarrow \mathrm{Fe}^{2+}+2 \mathrm{e}$.

This agrees with results from weight loss experiment; calculated corrosion rate values and inhibition efficiency follow similar pattern as weight loss experiment as evident in Fig 8 and Table 2. Corrosion rate decreased as the extract concentration increased while inhibition efficiency increased with increase in concentration.

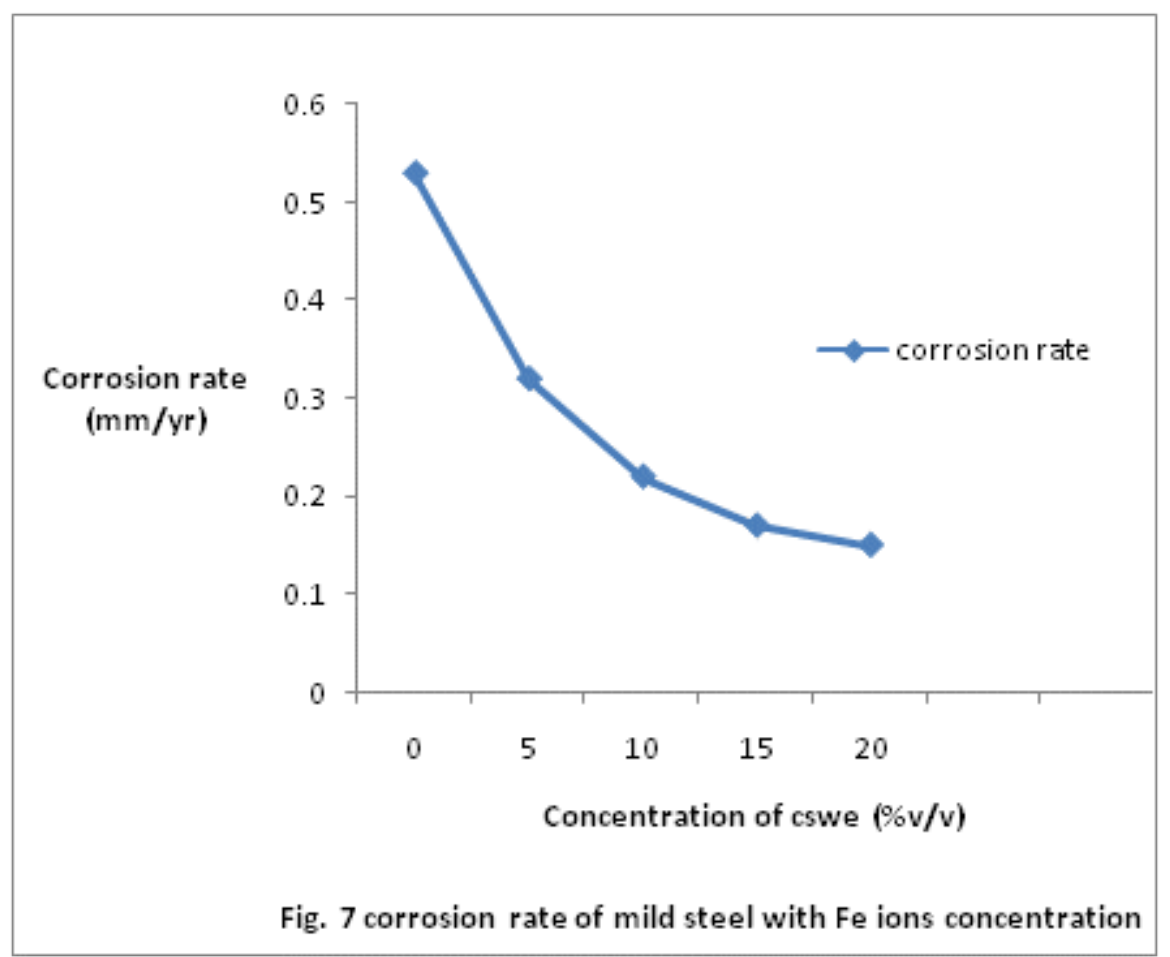


Table 2. Surface coverage and half life values at different temperatures

\begin{tabular}{|r|r|r|r|r|r|r|}
\hline \multicolumn{3}{|c|}{ surface coverage $(\Theta)$} & \multicolumn{3}{|c|}{ Half life ( days) } & \\
\hline 303 & 313 & 323 & 303 & 313 & 323 & \\
\hline 0 & 0 & 0 & 29.6 & 8.47 & 6.76 & \\
\hline 0.494 & 0.367 & 0.354 & 60.8 & 13.48 & 10.91 & \\
\hline 0.64 & 0.477 & 0.4 & 80.58 & 16.38 & 13.35 & \\
\hline 0.71 & 0.53 & 0.458 & 103.4 & 18.04 & 14.71 & \\
\hline 0.77 & 0.59 & 0.504 & 141.4 & 21.12 & 16.65 & \\
\hline
\end{tabular}

\section{Adsorption Isotherms}

Most natural inhibitors protect metal by forming protective film on metal surface. The extent of protection can be estimated by calculating the surface coverage of the metal. Surface coverage was calculated using the formula below

$\Theta=1-\frac{\text { CRinh }}{\text { CRblank }}$

CRinh \&CRblank (mm/yr) is corrosion rate in presence and absence of inhibitor. Values are shown in Table 2. Oguzie et al (2007) attributed the availability of such protective film to adsorption effect by organic inhibitors containing $\mathrm{S}$ and $\mathrm{N}$ atoms.

Adsorption study is used to describe the existence of higher concentration of any particular substance at the surface of a liquid or solid than is present in the bulk solution. Data obtained from thus study was filled into three adsorption models, Langmuir, Temkin and Frendlichisotherms, so as to ascertain the existence and nature of any particular substance on metal surface. The plots are shown in Fig 6-9.The oxidation reaction resulting to metal dissolution can be related closely to absorption of CSWE molecules on mild steel surface. Adsorption isotherms give information on metal-inhibitor interaction (Manimegalai 2015) and the reaction of metal surface and inhibitor. $(\Theta)$ Expresses the extent of coverage of inhibitor molecules on metal surface. The relationship between surface coverage and inhibitor molecules (concentration) is portrayed in these three adsorption isotherms. Langmuir isotherm was tested using equation (5),

$\frac{C}{\theta}=\frac{1}{\mathrm{Kad}}+C \ldots \ldots \ldots .5 \quad$ where $\mathrm{C}$ is inhibitor concentration $\Theta$ is surface coverage and $\mathrm{K}_{\mathrm{ad}}$ is the adsorption equilibrium constant. $\mathrm{K}_{\mathrm{ad}}$ represents the strength between adsorbate and adsorbent (Ating et al 2010)

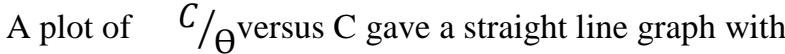

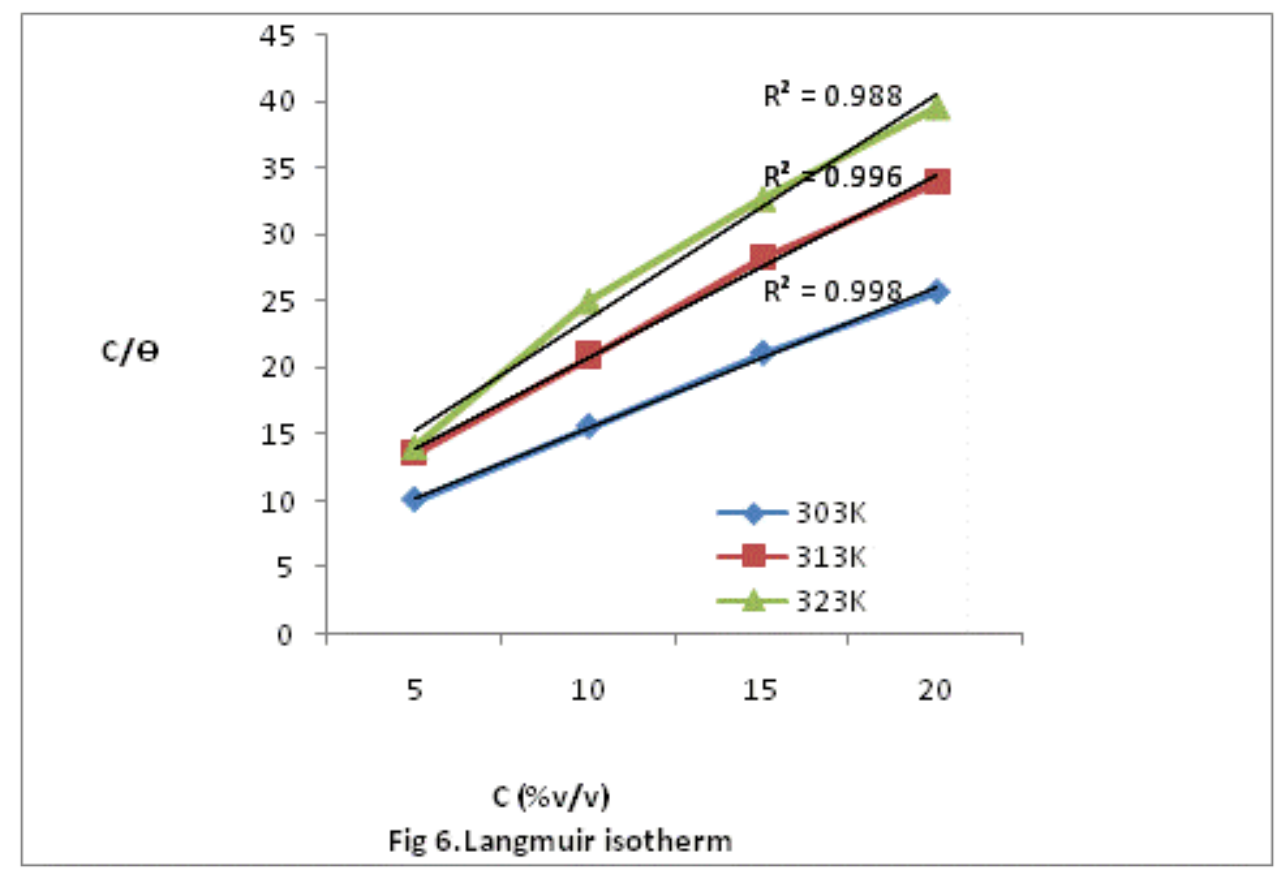

Correlation coefficient values $\left(\mathrm{R}^{2}\right)$ which is almost unity: the isotherm fitted even in higher temperatures.The degree of surface coverage as expressed by the Temkin isotherm was obtained by plottingӨagainst $\log C$ as presented in Fig. 8. A plot of $\log \theta$ against $\log C$ is shown in Fig 9 for Frendlich Isotherm. The correlation coefficient $R^{2}$ for all the isotherms shows that Langmuir isotherm is most fitted $\left(R^{2}\right.$ is from $0.998,0.996$ and 0.988 ) to describe the nature adsorption on mild steel surface. 


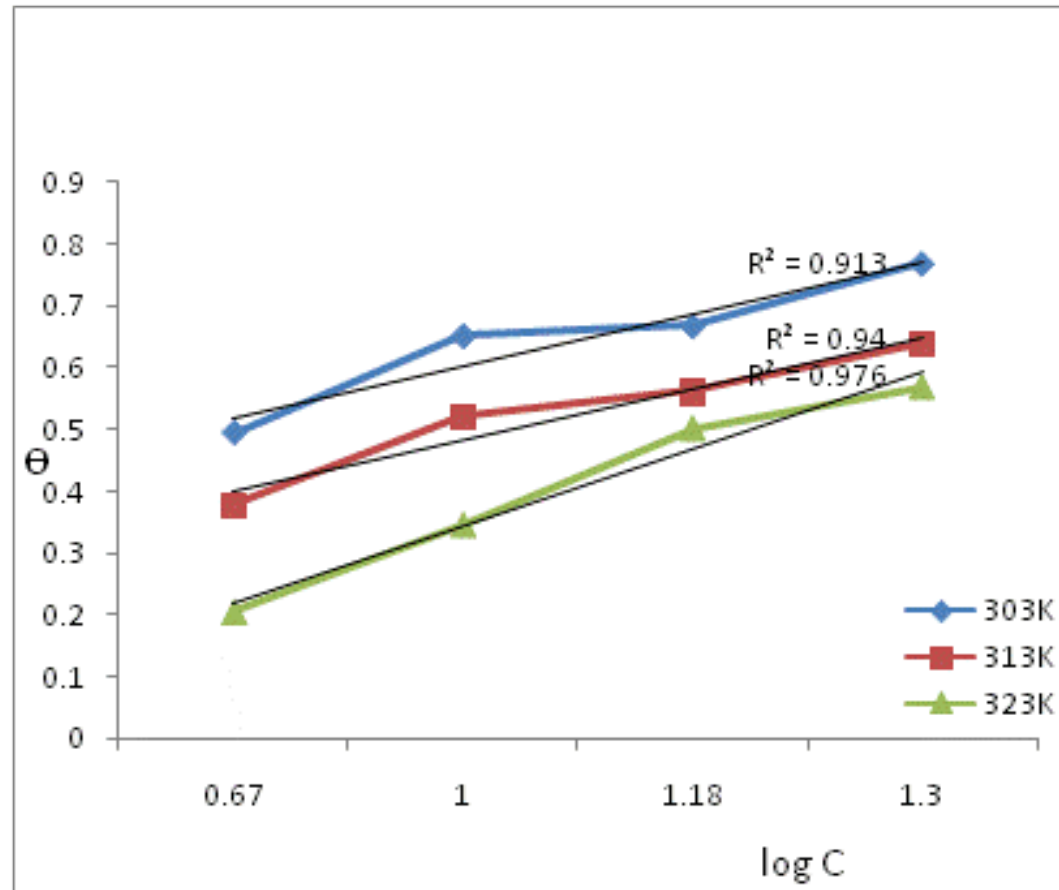

Fig 8. Temkim isotherm

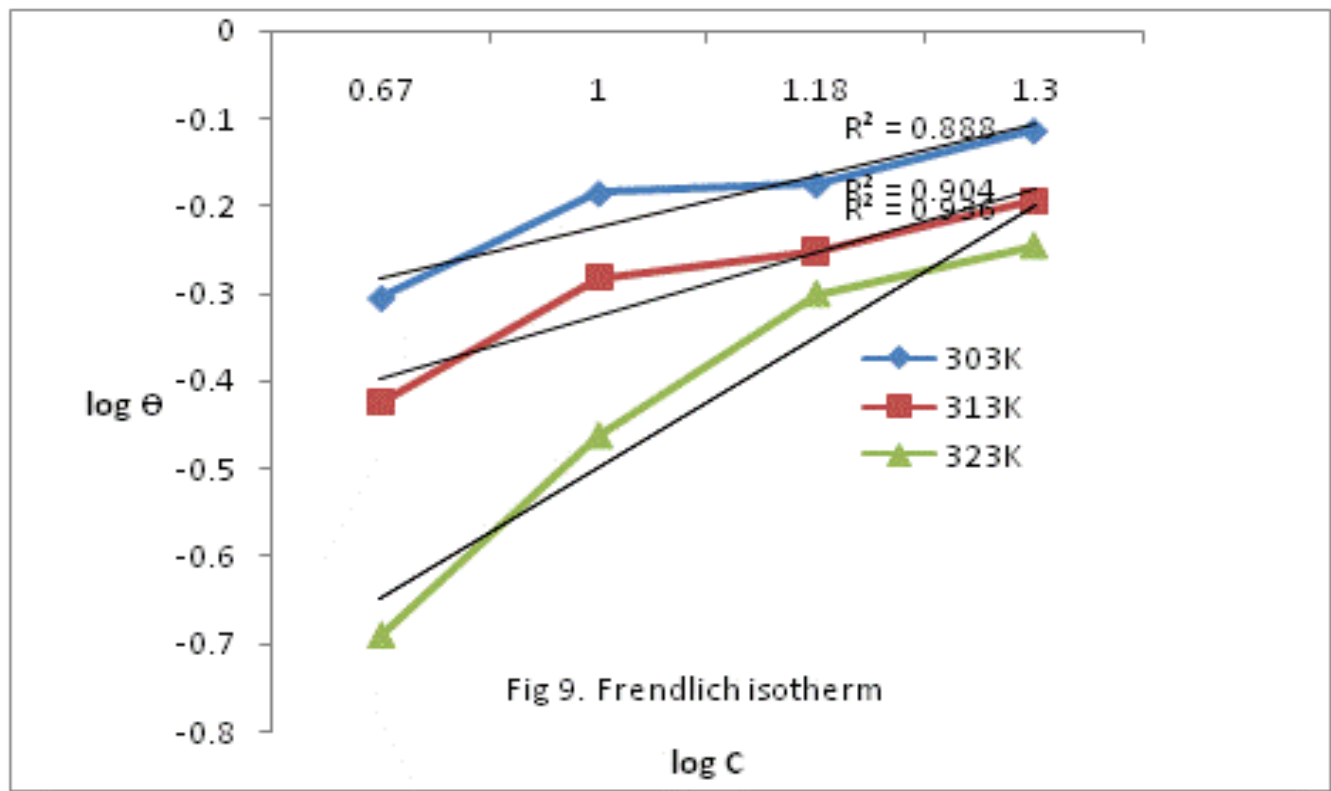

\section{Mechanism of Inhibition}

From the isotherms, the mechanism of inhibition of mild steel's corrosion is $0.5 \mathrm{M} \mathrm{HCl}$ by CSWE could be attributed to the adsorption of phytochemicals present in CSWE on mild steel surface producing a barrier or protective film which separates metal surface form the corrosive environment. Adsorption of metal surface is either physical (physisorption) or chemical (chemisorption). Physisorption depicts weak dipole- dipole attractions while Chemisorptions involves electron sharing or transfer between inhibitor molecules and metal ions. The interaction between metal surface and inhibitor in this work is rather weak. Hence as temperature increasesthe film is broken exposing mild steel to more attack by the environment. The resultant effect is an increase in corrosion rate and metal dissolution at these higher temperatures. Corn silk like most plants has constituents such as alkaloids, phenolic compounds, flavonoids and steroids which all contain the heteroatoms $\mathrm{O}, \mathrm{N}$ and $\mathrm{S}$. It is not possible to assign the inhibitive effect to any specific constituent (Janaina Cardozo da Rocha et al 2014). Generally speaking the afore mentioned hetero atoms meet the characteristics of corrosion inhibitors. The hydroxyl groups in them can be adsorbed on metal surface through $\mathrm{H}$ - bonding. 
These organic molecules exist in CSWE either as neutral molecules or in prorogated organic molecules in aqueous acidic solution. The molecular electron structure determines the effectiveness of a corrosion inhibitor. The corn silk water extract may have been absorbed on the surface of the metal on the basis of donoracceptor interactions between $\pi$ electrons of the aromatic ring and vacant d-orbital's. Ghulamullah et al reiterates that the adsorption mechanism of organic inhibitors at metal / solution interface may consist of one or more steps different ; replacement of water molecules initially adsorbed on metal surface by inhibitor molecules (step 1), and subsequently combination of inhibitor with metal ions in solution (step 2),

$\mathrm{Inh}_{\text {sol }}+\mathrm{xH}_{2} \mathrm{O} \rightarrow \mathrm{Inh}_{\text {ad }}+\mathrm{H}_{2} \mathrm{O}_{\text {sol }}$

$\mathrm{Fe}^{2+}+\mathrm{lh} \rightarrow \mathrm{Fe}^{2+}+2 e \ldots \ldots \ldots \ldots \ldots . . . \mathrm{step} 1$

$\mathrm{Fe}^{2+}+\operatorname{Inh} \rightarrow\left(\mathrm{Fe}^{2+}-\operatorname{lnh}\right)^{2+} \ldots \ldots . . . \mathrm{step} 2$

$(\operatorname{lnh}=$ inhibitor $)$

$\left(F e^{2 t}-\operatorname{lnh}\right)^{2+}$ is adsorbed on mild steel surface by weak forces of attraction - van der Waals to form a protective film on mild steel surface. The inhibitive effect of the film therefore depends on its stability and concentration.

\section{Conclusion}

Corn silk water extract has been found to be an effective inhibitor for mild steel in $0.5 \mathrm{M} \mathrm{HCl}$. Weight loss and AAS data were complimentary (inhibition efficiency at 303K, was $77.7 \%$ and $72.2 \%$ respectively from the two methods used).A decrease in weight loss of coupons and concentration of $\mathrm{Fe}$ ions leached into solution of the different concentrations studied reveal that CSWE is indeed a corrosion inhibitor of mild steel in $0.5 \mathrm{M}$ $\mathrm{HCl}$. Inhibitive property is attributed to the hetero atoms $\mathrm{N}, \mathrm{O}$ and $\mathrm{S}$ presence in its phytochemical composition. Inhibition efficiency increased with increase in concentration of inhibitor and decreased with increase in temperature. CWSE was observed to have maximum inhibition within the first three days and is affected by microbial activities in the environment thereafter. Experimental data fitted intoLangmuuir, Temkin and Frendlich isotherms shows the Langmuir isotherm more appropriate to describe the adsorption process, suggesting the existence of weak van der Waals forces of attraction on metal surface. These were responsible for theformation of a protective film as barrier between metal and corrosive environment.

\section{References}

[1]. Alaemary, G A; Refaat, A S. Crystallization of calcium oxalate monohydrate crystals (COM) in the presence of corn silk and trigonellafoenumGraecum. World Journal of Pharmaceutical Research, 5 (3) 1764-1777.

[2]. Alaneme, K K; Daramola, Y S; Olusegun, S J; Afolabi, A S (2015). Corrosion inhibition and adsorption characteristics of Rice Husk extract on mild steel immersed in $1 \mathrm{M} \mathrm{H}_{2} \mathrm{SO}_{4}$ and $\mathrm{HCl}$ solutions. International Journal of Electrochemical Science, 10 (2015) 3553-3567.

[3]. Ating, F B; Umoren, E I; Udosoro(2010). Leaves extract of Ananassativum as green inhibitor for Aluminium in hydrochloric acid solutions. Green Chemistry Letters and Reviews, 3 (2), 61-68.

[4]. Ebenso, E E; Obot, I B ;Murulana, L C(2010). Quinoline and its derivatives as effective corrosion inhibitors for mild steel in acidic media. International Journal of Electrochemical Science, 5 (2010) 1574 -1586.

[5]. Ebrahimzadel, M A; Hosseinimehr, S J ; Hamidinia, A; Jafari , M (2008). Antioxidant and free radical scavenging activity of feijoasellowiana fruit peels and leaves. Pharmacologyonline 1: 7-14.

[6]. Eddy, U M; Ameh, P O; Gwarzo, M Y; Okop , I J; Dodo, S N (2013). Physiochemical study and corrosion inhibition potentials of Ficustricopoda for Aluminium in acidic medium. PortugaliaeElectrochimicaActa ,3(2)79-93.

[7]. Emmanuel, S A; Olutayo, O; Salisu, A; Saheed, O A; Godwin , E (2016). Chemical evaluation, free radical scavenging activities and antimicrobial evaluation of methanolic extracts of corn (Zeamays ). Journal of advances in medical and pharmaceutical sciences, 9 (4) $1-8$

[8]. El- Etre, A Y (2016). Khillah extract as inhibitor for acid corrosion of SX316 steel. Applied Surface Science, , 252, 8521-8525.

[9]. Etuok, UM; Umoren, SA and Udoh, AP (2012). Synergistic inhibition Effects between leaves and stem extract of Sidaacuta and iodide ions on mild steel corrosion in $1 \mathrm{M} \mathrm{H}_{2} \mathrm{SO}_{4}$. African Journal of Chemistry, 5 (2012) 319-325.

[10]. Guo, J; Tonjun, L; Linna, H; Yongmei, L (2009). The effect of corn silk on glycaemic metabolism, Nutrition and Metabolism .2009 , 6:47.

[11]. Hart, K G; Okorosaye - Orubite, K; James, OA (2016). Corrosion inhibition of copper in sea water by Xanthosomaspp leaves extract (XLE) . International Journal of advanced research in Chemical Science, 3 (12) 1-7.

[12]. Janaina Cardozo da Rocha; Jose Antonio da Cunha Ponciano Gomes; ElianeD'Elia (2014). Aqueous extract of mango and orange peel as green inhibitor for carbon steel in hydrochloric acid solution. Mat. Res. 17(6) Sao Carlos. http://dx.doi.org/10.1590/15161439.285014 .

[13]. Khadijah, M E; Awra, O A; Bayan, A T; Naija, M A (2015). Corrosion and corrosion inhibition of cast iron in Hydrochloric acid $(\mathrm{HCl})$ solution by cantaloupe (cucumismelo ) as green inhibitor . African Journal of Pure and Applied Chemistry, 9 (3) 39-49.

[14]. Magarita, K; Kristy, G; Alla, F; Liz , A (2012). Novel corrosion inhibitors derived from Agricultural by - products: Potential applications in water treatment. Paper presented to NACE international, corteccorporation . 4119 white Bear parkway. St Paul , Minnesota , 55110, USA.

[15]. Maksimovic , Z; Dorde, M; Nada, K (2005). Phenolic content and antioxidant activity of Maydis stigma extracts. Bioresources Technology, 96 (8) 873-877.

[16]. Manimegalai , S; Manjula , P; (2015). Thermodynamic and Adsorption studies for corrosion of mild steel in aqueous media by sargasamswartzii( Brown algae ). Journal of material Enviromentalscience , 6 (6), 1629-1637.

[17]. Nahle, A (2005). Inhibition of corrosion of iron in $\mathrm{HCl}$ solution by semicarbazones andthiosemicabarzones, Bulletin of Electrochemistry, 21 (6) 275-281. 
[18]. Negm, N A; Al- mayouf; Khan , M ; Almazroa, H Z (2012). Corrosion inhibitory action of some plants on the corrosion of mild steel in acidic media. Arabian Journal of chemistry, 1-7.

[19]. Nurhanan, A R; Wan, W I (2012). Evaluation of phenol content and antioxidant activities of some selected organic and aqueous extracts of silks ( Zea Mays) hairs. Journal of Medical and Biomedical (JOMB) 1 (1) 48-50

[20]. Oguzie, E E; Li, Y; Wang, P H (2007). Corrosion inhibition and adsorption behavior of methionine on mild steel in sulphuric acid and synergistic effect of iodide ion. Journal of colloid and interface science, 310 (2007) 90-98.

[21]. Okoafor, P C and Ebenso, E E (2010). Inhibitive action of Carica Papaya extracts on corrosion of mild steel in acidic medium and their adsorption characteristics. Pigments and Resins Technology, 36 (3) 134-140.

[22]. Oloruntoba, J A; Abbas, J A; Olusegun, S J (2012). Water hyacinth (eiclihorniacrassipes) leaves extract as corrosion inhibitor for A1S1 1030 steel in sea water In: Laryea, S; Agyepong, S A; Leiringer, R and Huges, W E (eds), Proceedings of $4^{\text {th }}$ West Africa Built Enviroment Research (WABER) conference, 24-26 July 2012, Abuja , Nigeria, 1131

[23]. Olusegun, S J; Adeiza, B A; Ikeke, K I, Bodurin, M O (2013). Urcas extract as corrosion inhibitor for Jatrophacurcas as corrosion inhibitor for mild steel in $1 \mathrm{M}$ hydrochloric acid. Journal of Emerging Trends in Engineering and Applied sciences, 4 (1) 138 - 143.

[24]. Rehan , H H (2003). Corrosion control by water soluble extracts from leaves of economic plants. Matt.-wiss. U. werks to fftech, 34 , 232-237.

[25]. Paulina Arellanes - Lozada,, Octavio Oliveares- Xometl, Natalya V. Likhanova, Irina Lijanova, M. A Ramirez- Garnica, Elsa M . Arce- Estranda. Evaluation of corrosion inhibiting effect of ionic liquid ( N- dimethyl- N- di (cocoalkyl) Ammonium methyl sulphate) on API 5L X52 steel in HCl acid. International journal of electrochemical science 10 (2015) 2776-2790

[26]. Singh, A K; Quraishi (2012). Study of some bidentate Schiff bases of Isatin as corrosion inhibitors for mild steel in Hydrochloric acid solution. International Journal of Electrochemistry , 7 , 3222-3241.

[27]. Taissa, F S; Mariana, M; Vanessa, V T; Eliane, D (2015). Inhibitory action of Ilex paraguariensis extract on the corrosion of carbon steel in $\mathrm{HCl}$ solution. International Journal of Electrochemical Science, 10 (2015) 22-23.

[28]. Tian, J ; Chen, H; Chen, S; Xing, L; Wang, Y; Wang, J (2013). Comparative studies of the constituents, antioxidants and anticancer activities of extracts from different varieties of corn silk. Food funct. 2013 (4) 1526-1534

[29]. Velazquez, D V O (2005). Zea Mays L. extract to modify glomerular function and potassium urinary excretion in conscious rats. Phytomedicine 12 (5) 363-369

[30]. Yusuf, T A; Gundu, D T; Oseni, M I; Bolaji, Bukola , O ; Ismaila SO (2013). Evaluation of corn water for corrosion inhibition extracts. International Journal of Engineering and Science, 2 (8) 31-35. 